\title{
LEXICOGRAFIA E ENSINO: REFLEXÕES NECESSÁRIAS
}

\author{
Rejane Centurion* \\ Milena Borges de Moraes**
}

\begin{abstract}
Resumo: A partir de um tratamento inicial acerca do que vem a ser a ciência da Lexicografia e os principais tipos de obras lexicográficas, pretendemos estabelecer uma discussão a respeito da utilização de dicionários no ensino de Língua Portuguesa. Nossa hipótese é a de que, a partir da análise de atividades propostas em materiais didáticos direcionados à Educação Básica, faz-se necessário estabelecer discussões/reflexões sobre a lexicografia no ensino de língua para que se implemente um trabalho mais produtivo com dicionários. Como procedimento analítico, observamos em dois materiais didáticos (BRASIL, 2012 e PENTEADO et al., 2009), a mobilização de uso de dicionários e do gênero verbete. $\mathrm{O}$ aparato teórico tomou como referência obras como as de Antunes (2012), Biderman (1984 e 1998), Krieger (2007), entre outras. Como resultado, podemos afirmar que se necessita o estabelecimento de discussões sobre lexicografia na escola e nos cursos de formação, bem como mudanças na aplicação de atividades em material didático direcionado a aulas de Língua Portuguesa.
\end{abstract}

Palavras-chave: Lexicografia; dicionários; ensino; Língua Portuguesa; material didático.

* Universidade do Estado de Mato Grosso, Universidade de São Paulo, FAPESP. ** Universidade do Estado de Mato Grosso, Universidade de São Paulo, FAPEMAT. 


\begin{abstract}
From an initial treatment about what is the science of Lexicography and the main types of lexicographical works, we intend to establish a discussion regarding the use of dictionaries in Portuguese language teaching. Our hypothesis is that, from the analysis of proposed activities on didactic materials targeted to Basic Education, it is necessary to establish discussions/reflections about lexicography in language teaching in order to implement a more productive work with dictionaries. As analytical procedure, we observed in two didactic materials (BRASIL, 2012 and PENTEADO et al., 2009), the mobilization of use of dictionaries and the genre entry. The theoretical apparatus took as reference works like Antunes (2012), Biderman (1984 and 1998), Krieger (2007), among others. As a result, we can state that its necessary the establishment of debates about lexicography at school and in training courses and changes in the implementation of activities in didactic material targeted to Portuguese language lessons.
\end{abstract}

Key words: Lexicography; dictionaries; education; Portuguese language; didactic material.

\title{
1 Considerações iniciais
}

Os Livros Didáticos de Língua Portuguesa (doravante LDLP), a partir da implantação, pelo Ministério da Educação (MEC), do Programa Nacional do Livro Didático (PNLD), passaram a ser objeto de estudo crescente por parte de teóricos da área, os quais refletem sobre sua estrutura, organização, metodologia educacional, fundamentação e conteúdo para o efetivo ensino da Língua Portuguesa. A partir de 2006, outra preocupação veio se somar com a política do PNLD, voltada à tipologia lexicográfica adequada para cada nível de escolaridade. Devido a isso, um número significativo de diferentes tipos e títulos de dicionários de Língua Portuguesa foi distribuído às escolas públicas como recurso para subsidiar os professores em sala de aula.

Diante dessa conjuntura e com o intuito de estabelecer uma discussão a respeito da utilização de dicionários no ensino de Língua Portuguesa, sobretudo no que diz respeito às atividades oriundas de materiais didáticos utilizados em aulas de Língua 
Portuguesa, os quais se propõem a instigar a mobilização do uso de dicionários, propomos o presente trabalho.

Vale notar que o LDLP costuma ser, quase que exclusivamente, o material didático predominante de leitura e estudo em sala de aula, reforçando a necessidade de sua adequação a um processo de ensino/aprendizagem que privilegie o uso efetivo da Língua Portuguesa. Isso leva-nos ao questionamento sobre a qualidade das propostas de utilização de dicionários no ensino de Língua Portuguesa presentes nos LDLP. As atividades estimulam o aluno apenas em busca de uma resposta pontual? A consulta restringe-se ao binômio certo-errado? Abordam o uso do dicionário como um instrumento de apoio didático importante para os ensinamentos da língua e da cultura? Há necessidade de se estabelecer discussões sobre lexicografia na escola e nos cursos de formação, bem como mudanças na aplicação de atividades em material didático direcionado a aulas de Língua Portuguesa? São questões como essas que nortearão nossa reflexão a partir da análise de obras didáticas.

Para discutirmos tais inquietações, mobilizamos os apontamentos teóricos de Antunes (2012), Biderman (1984 e 1998), Krieger (2007), dentre outros, bem como orientações dos PCN do Ensino Fundamental (BRASIL, 1998), e elegemos como corpus empírico materiais didáticos utilizados em aulas de Língua Portuguesa, os quais pudessem mostrar como mobilizam o uso de dicionários e do gênero verbete.

A organização do presente artigo encontra-se da seguinte forma: após esta introdução, apresentaremos um breve histórico da constituição da Lexicografia e os principais tipos de obras lexicográficas. Em seguida, explanaremos sobre o dicionário como instrumento de ensino e a política federal que o envolve. Na sequência, apresentaremos a análise dos materiais didáticos selecionados e, por fim, as considerações finais e as referências utilizadas. 


\section{Lexicografia: breves apontamentos}

A Lexicografia, uma das ciências do Léxico, traduz-se como a "ciência dos dicionários" (BIDERMAN, 1998, p. 15). É comum tratar especificamente a elaboração destes como estudo lexicográfico; já os trabalhos sobre os dicionários, como estudo metalexicográfico. De acordo com Biderman (1984), apesar de a verdadeira lexicografia iniciar-se nos tempos modernos, houve obras de cunho vagamente lexicográfico já na Antiguidade e Idade Média. Assim, os glossários produzidos pela escola grega de Alexandria (sécs. III a I a.C.), auxiliares à leitura de textos homéricos, já podiam ser considerados como tentativas reveladoras da preocupação com a compreensão que uma palavra viesse a ter. Tais glossários eram elaborados por filólogos ou gramáticos, os quais se preocupavam, respectivamente, ou com a compreensão dos textos literários, ou com a correção de erros linguísticos.

$\mathrm{Na}$ Idade Média, representaram destaque as Etimologias (como as de Santo Isidoro de Sevilha); no entanto,

têm escasso ou nulo valor científico e linguístico, sendo muito fantasistas. Baseiam-se numa concepção mística do mundo e da linguagem que tende a referir a língua e as palavras a um sistema de significação que se reporta a Deus, adulterando-lhes, pois, a natureza. Na verdade, documentam o mundo cultural da Idade Média e sua concepção de universo (BIDERMAN, 1984, p. 1).

Neste mesmo período, os glossários continuaram desempenhando grande importância. Coutinho (1976, p. 39) afirma que as glosas representam um "meio auxiliar excelente para o conhecimento da lexicografia do latim" ${ }^{1}$ e destaca a

\footnotetext{
1 "O maior repositório dessas glosas é o Corpus Glossariorum Latinorum, de G. Loewe e G. Goetz, editado em Leipzig (1889-1923) e o Glossaria latina, publicado por W. M. Lindsay, por ordem da Academia Britânica (1926-1931)" (COUTINHO, 1976, p. 39).
} 
importância, para o estudo das línguas neolatinas, das glosas de Reichenau e de Cássel. As de Reichenau (séc. VIII d.C.) receberam esse nome pelo fato de o manuscrito ter sido por muito tempo conservado na abadia de Reichenau. Consta de duas partes, sendo uma apensa ao texto da Vulgata (versão latina da Bíblia) e a outra sem referência a nenhum texto específico, as quais totalizam pouco mais de 2.000 vocábulos, dispostos em ordem alfabética. "São listas de palavras [...] de difícil compreensão para a época do autor, traduzidas no vernáculo românico da região" (BIDERMAN, 1984, p. 1-2). As de Cássel (séc. IX d.C.), inicialmente pertencentes à biblioteca de Cássel, compreendem 265 palavras traduzidas do latim para o vernáculo germânico da região, "dispostas segundo as coisas ou objetos a que se referem: partes do corpo humano, animais domésticos, casa e seus pertences, vestimentas, utensílios, etc" (COUTINHO, 1976, p. 40).

Foi, pois, a partir do Renascimento que surgiram os dicionários no formato dos conhecidos atualmente:

Quando o homem renascentista começou a ampliar os seus horizontes culturais abandonando de vez a sua reclusão medieval dentro de sua própria cultura, descobriu a necessidade de aprender línguas, evidentemente as línguas européias mais faladas na época (século XVI). Além da consciência adquirida da distância entre o latim e as línguas vernáculas do seu tempo, o homem renascentista precisava de outros instrumentos de intercâmbio linguístico num mundo que se abria para um novo diálogo e trocas entre as jovens nações européias. Assim, multiplicam-se os dicionários bilingues na Espanha, na França, na Itália, em Portugal [...] (BIDERMAN, 1984, p. 2).

Em relação à lexicografia portuguesa, cabe destacar o Vocabulario Portuguez e Latino, de Raphael Bluteau, publicado em Coimbra, entre 1712 e 1721, e considerado por Biderman (1984, p. 4), "o melhor dentre os mais antigos dicionários do português". Para ela, tal obra não se caracteriza unicamente como um dicionário bilíngue, mas um projeto misto, haja vista seu autor 
não apenas ter fornecido a tradução dos termos, mas ter constituído um dicionário de Língua Portuguesa na parte relativa à língua. Com característica enciclopédica, apresenta muita e variada informação tanto sobre o latim quanto sobre o português, além de "alistar todos os autores portugueses que compuseram o corpus que forneceu o exemplário das abonações dos verbetes”.

Depois disso, destacamos a obra de Antonio de Moraes Silva, Diccionario da Lingua Portugueza, marcando o início da lexicografia moderna. Sua edição príncipe se deu em 1789, ainda no século XVIII, mas recebeu várias edições no decorrer do século XIX. A seguir, no século XX, a obra de Aurélio Buarque de Holanda Ferreira, Novo Dicionário da Língua Portuguesa, com primeira edição em 1975 e, finalmente, no século XXI, o Dicionário Houaiss da língua portuguesa, de Antonio Houaiss, do ano de 2001.

Estas obras representam apenas alguns dos trabalhos lexicográficos publicados nos períodos em questão. Atualmente, são vários os tipos de dicionários disponíveis aos leitores/usuários da língua. A partir de Biderman (1984), elencamo-los a seguir:

a) Dicionário padrão da língua: é o tipo mais comum, apresentando várias modalidades dependendo da destinação e do tipo de usuário - o infantil (5.000 verbetes), o escolar (10.000 verbetes), o padrão (50.000 verbetes) e os "thesauri" (de 100.000 a 500.000 verbetes). Funciona como um instrumento (normativo) de orientação aos seus consulentes sobre os significados e os usos das palavras de forma que possam se expressar com a maior precisão e propriedade possíveis, utilizando o tesouro léxico que a língua disponibiliza.

b) Dicionário ideológico: organiza os conceitos em campos semânticos, ao invés de ordenar as palavras alfabeticamente. O primeiro foi elaborado por Comenius, no século XVII.

c) Dicionário histórico: são vários os tipos, podendo se basear no vocabulário e língua de determinada época histórica ou se caracterizar como pancrônico (ou etimológico). Este, 
parte da perspectiva contemporânea da língua, se ocupa de estágios anteriores do idioma remontando à origem das palavras, tentando acompanhar a evolução histórica dos vocábulos e assinalando os diferentes valores semânticos assumidos no decorrer do tempo.

d) Dicionários de tipo especial: são dicionários especializados num domínio específico do conhecimento (Dicionário de Análise do Discurso, Dicionário Médico Ilustrado, Dicionário dos Animais do Brasil, entre outros).

As enciclopédias diferem dos dicionários por se caracterizarem estes, linguísticos, e aquelas, culturais, "obras de referência que buscam reunir o máximo de informação sobre os mais variados domínios do conhecimento para consumo do público em geral, e não de especialistas" (BIDERMAN, 1984, p. 16). Há dicionários, no entanto, que se caracterizam como enciclopédicos, trazendo mais do que informações linguísticas aos verbetes, como afirma Biderman (1998, p. 136): “[...] alguns dicionários de língua têm características claramente enciclopédicas, incluindo informações das mais variadas naturezas, sobretudo científicas". Welker (2004, p. 47) aponta que "os dicionários gerais extensos, ou tesouros, são enciclopédicos em maior ou menor grau, dando informações além da simples definição" e cita como exemplo, em Língua Portuguesa, o Dicionário Houaiss.

Apesar de o dicionário padrão da língua ser o mais comum, diferentes tipos circulam entre os usuários da língua, ainda que seja em espaços específicos, fato que nos leva a acreditar que seja papel da escola e dos cursos de formação de professores a promoção de discussões acerca dessa diferenciação. Tal reflexão fez, então, com que verificássemos em LDLP se havia uma preocupação, quando da apresentação de conteúdo lexicográfico, em se esclarecer ao aluno a existência de uma tipologia lexicográfica. Nossa preocupação não é a de inserção de conteúdos aprofundados aos alunos da Educação Básica, mas a de verificar se, de alguma forma, obras didáticas se atentam à questão. 


\section{O dicionário como instrumento de ensino}

Acompanhando os usuários da língua há séculos, o dicionário, se utilizado adequadamente, pode exercer um importante papel junto às atividades de ensino de língua. Podemos afirmar, a partir de Krieger (2007, p. 297), que a sua configuração ultrapassa 0 aspecto linguístico, sendo portador de representações culturais e da memória de um povo, vindo a desempenhar muitas funções históricas, além do papel de arquivo de memória do componente lexical: "Ao registrarem, de modo sistematizado, os itens lexicais de uma língua dão coesão às sociedades e projeção às suas culturas, porquanto definem a identidade linguística dos povos". No entanto, "ainda não podemos registrar um grande interesse da escola pelos estudos em torno do dicionário" (ANTUNES, 2012, p. 138), já que a realidade é a de que o componente gramatical ainda prevalece sobre o lexical em sala de aula, o que leva Antunes (2012, p. 20) a facilmente chegar à constatação de que, em relação ao tempo preenchido nas aulas de português, "a atenção concedida ao estudo do léxico tem um caráter breve e insuficiente. Ocupa assim um lugar adicional". Tal constatação pode ser verificada também no ensino de Língua Espanhola, a partir de Fernández (2007, p. 169, tradução nossa), da Universidad de Alicante:

[...] ainda que a chamada 'lexicografia didática' tenha passado por um desenvolvimento espetacular nos últimos tempos, o lugar que o dicionário ocupa no ensino do espanhol está a séculos de alcançar aquilo que o corresponde, considerando sua reconhecida utilidade como instrumento de aprendizagem. ${ }^{2}$

2 " [...] aunque la llamada 'lexicografía didáctica' ha experimentado um espectacular desarrollo em los últimos tiempos, el lugar que ocupa el diccionario en la enseñanza del español esta lejos de alcanzar el que le corresponde, teniendo en cuenta su reconocida utilidad como instrumento de aprendizaje" (FERNÁNDEZ, 2007, p. 169). 
As reflexões de Antunes (2012, p. 136-7) detêm-se ao uso do dicionário monolíngue de Língua Portuguesa, já que tem em mente o ensino de uma língua materna. A partir de diversas concepções de dicionário elencadas, a autora chama a atenção para a necessidade de percebermos as palavras "para além de sua natureza estritamente linguística", ou seja, "para além de sua forma, de sua classe, de sua função sintática, para situá-la no âmbito dos usos, da representação cultural, da memória social que atesta o percurso da língua". Afinal, é relevante observar a palavra, mesmo em seu "estado dicionário", como elemento constitutivo do universo cultural dos grupos humanos.

Vale notar que Antunes (2012) critica o fato de o dicionário não ser explorado como um instrumento didático, no ensino de línguas, restringindo-se, na maioria dos casos, como um "guia ortográfico", um "tira-dúvidas", ou seja, persiste o binômio certoerrado. Além disso, ressalta a importância de sua qualidade quando da utilização na escola, sendo que o dicionário escolar precisa sofrer subdivisões considerando as diferentes etapas de ensino, com suas acentuadas diferenças no que se refere à quantidade de verbetes, à seleção das palavras que compõem as entradas, o conjunto das informações do verbete, o nível de linguagem, os tipos de definições, as informações complementares, a presença de ilustrações, entre outros elementos, para atender às necessidades dos alunos tanto do Ensino Fundamental quanto do Ensino Médio.

Diante isso, é preciso observar que essas preocupações em torno da tipologia lexicográfica já fazem parte de uma política federal, por meio do Ministério da Educação, juntamente com o PNLD, conforme explicitaremos a seguir (na seção 4).

Krieger (2007) aponta que, em relação à escolha do dicionário, os critérios podem ser semelhantes aos da escolha de livros didáticos: relação de conteúdos, adequação ao nível de ensino e correção da informação veiculada, destacando o fato de que o conjunto de informações oferecido pelo dicionário auxilia o desenvolvimento cognitivo do aluno, sendo um lugar privilegiado de lições sobre a língua, vindo a funcionar como "um efetivo 
instrumento didático, auxiliando no desenvolvimento de muitas competências básicas inerentes a todo aprendizado" (p. 298).

Antunes (2012, p. 144) pondera que é relevante que se crie na escola o hábito de consultar um dicionário em atividades de leitura e de escrita, de modo a fomentar a atitude de pesquisa e fortalecer a autonomia do aluno em empreender uma ação de busca da informação de que precisa, a saber: buscar informações sobre as várias acepções de uma palavra, seus contextos de uso, suas possíveis combinações, sua etimologia, dentre outras informações sobre o léxico da língua, com intuito, sobretudo, "de promover a ampliação do repertório lexical do aluno". Na verdade, é preciso ressignificar as finalidades de uso do dicionário nas aulas de português, "o que ultrapassa até mesmo a identificação do sentido de uma palavra, uma vez que somente o contexto de uso é que vai definir, entre os sentidos possíveis, aquele que de fato foi ou deve ser atualizado".

O dicionário, assim como a gramática, é considerado um instrumento linguístico, porém não ganha o mesmo prestígio nos meios escolares; pelo contrário, exerce um papel mais restrito, inclusive limitado enquanto um instrumento didático para o ensino de Língua Portuguesa, conforme enfatizado pelas autoras supracitadas. Nessa esteira, nossa hipótese é a de que atividades oriundas de materiais didáticos, as quais envolvam conhecimento lexicográfico, ainda induzam ao uso limitado dele.

\section{O dicionário e a política federal}

As políticas públicas em torno de livro didático no Brasil iniciaram em 1929 e, no decorrer dos anos, sofreram diversas alterações, inclusive no nome do programa de execução. Atualmente, essa política é desenvolvida pelo PNLD, vinculado ao Ministério da Educação e Fundo Nacional de Desenvolvimento

\footnotetext{
${ }^{3}$ Informações disponíveis em: http://www.fnde.gov.br/programas/livro-didatico/ livro-didatico-apresentacao. Acesso em: jul. 2013.
} 
da Educação, e tem por objetivo "prover as escolas públicas de ensino fundamental e médio com livros didáticos e acervos de obras literárias, obras complementares e dicionários". ${ }^{3}$ Para isso, essas instâncias legitimadas propõem editais públicos para avaliação, aquisição e distribuição gratuita dessas obras.

O livro didático, de acordo com Coracini (1999), tornouse um elemento constitutivo do processo educacional brasileiro, tendo como função primordial dar certa forma ao conhecimento; "forma" no sentido de seleção e hierarquização do chamado "saber". Em termos de vendas, são os livros mais vendidos no Brasil, principalmente aqueles que trazem os roteiros mais detalhados para facilitar a compreensão e o dia a dia do professor, com respostas prontas e tidas como corretas, sugestões de provas, entre outras vantagens para que o percentual de erro do professor seja minimizado.

No que diz respeito aos dicionários, a partir de 2001 o PNLD passou a contemplar a lexicografia, selecionando e adquirindo dicionários de Língua Portuguesa aos alunos do ensino fundamental. Porém, o processo de avaliação dos dicionários a partir de 2005 adotou novas diretrizes, representando uma mudança com relação aos processos anteriores, principalmente no estabelecimento de uma divisão das obras lexicográficas em três tipos, cada um deles caracterizado não só pela quantidade de verbetes, mas, sobretudo, pela adequação aos diferentes níveis de ensino dos alunos a que se destinam. Isso por considerar que os alunos têm necessidades específicas conforme o nível e/ou etapa de aprendizagem em que se encontram.

As novas diretrizes de 2005 também se diferenciam quanto à distribuição de dicionários, pois em vez de entregar um dicionário para cada aluno, criam-se acervos lexicográficos para a sala de aula do ensino fundamental, priorizando a utilização do material no espaço escolar.

Em 2012, o PNLD/Dicionários adotou a avaliação e divisão das obras lexicográficas em quatro tipos, e a aquisição e a distribuição gratuita de dicionários de Língua Portuguesa às escolas 
de ensino fundamental e médio da rede pública, inclusive na modalidade Educação de Jovens e Adultos. Assim, a proposta consiste em distribuir às escolas quatro acervos de dicionários, sendo que cada acervo reúne obras de acordo com a etapa de ensino a que se destine, conforme os quatro tipos abaixo:

Dicionários de tipo 1: $1^{\circ}$ ano do ensino fundamental; mínimo de 500 e máximo de 1.000 verbetes; proposta lexicográfica adequada às demandas do processo de alfabetização inicial.

Dicionários de tipo 2: $2^{\circ}$ ao $5^{\circ}$ ano do ensino fundamental; mínimo de 3.000 e máximo de 15.000 verbetes; proposta lexicográfica adequada a alunos em fase de consolidação do domínio tanto da escrita quanto da organização e da linguagem típicas do gênero dicionário.

Dicionários de tipo 3: $6^{\circ}$ ao $9^{\circ}$ ano do ensino fundamental; mínimo de 19.000 e máximo de 35.000 verbetes; proposta lexicográfica orientada pelas características de um dicionário padrão de uso escolar, porém adequada a alunos dos últimos anos do ensino fundamental.

Dicionários de tipo 4: $1^{\circ}$ ao $3^{\circ}$ ano do ensino médio; mínimo de 40.000 e máximo de 100.000 verbetes; proposta lexicográfica própria de um dicionário padrão, porém adequada às demandas escolares do ensino médio, inclusive o profissionalizante (BRASIL, 2012, p. 19).

Cada acervo desse é acompanhado do livro Com direito à palavra: dicionários em sala de aula (BRASIL, 2012), cujo objetivo vem a ser o de apresentar informações referentes às características gerais desses acervos, bem como o de oferecer aos docentes subsídios teóricos e metodológicos para explorarem o dicionário produtivamente na proposição de atividades voltadas ao desenvolvimento das competências visadas nas respectivas fases de ensino.

Isso posto, é importante assinalar que os Parâmetros Curriculares Nacionais (BRASIL, 1998, p. 36) orientam novos tipos de trabalho na disciplina de Língua Portuguesa, incluindo-se, dentro do eixo REFLEXÃO, novos conteúdos, desenvolvidos sobre os do eixo USO, os quais possibilitem "análise do funcionamento da linguagem em situações de interlocução, na escuta, leitura e 
produção, privilegiando alguns aspectos linguísticos que possam ampliar a competência discursiva do sujeito", dentre eles, o item três, léxico e redes semânticas, o qual nos interessa neste estudo:

Ampliação do repertório lexical pelo ensino-aprendizagem de novas palavras, de modo a permitir:

* escolha, entre diferentes palavras, daquelas que sejam mais apropriadas ao que se quer dizer ou em relação de sinonímia no contexto em que se inserem ou mais genéricas/mais específicas (hiperônimos e hipônimos);

* escolha mais adequada em relação à modalidade falada ou escrita ou no nível de formalidade e finalidade social do texto;

* organização das palavras em conjuntos estruturados em relação a um determinado tema, acontecimento, processo, fenômeno ou mesmo objeto, como possíveis elementos de um texto;

* capacidade de projetar, a partir do elemento lexical (sobretudo verbos), a estrutura complexa associada a seu sentido, bem como os traços de sentido que atribuem aos elementos (sujeito, complementos) que preencham essa estrutura;

* emprego adequado de palavras limitadas a certas condições histórico-sociais (regionalismos, estrangeirismos, arcaísmos, neologismos, jargões, gíria);

* elaboração de glossários, identificação de palavras-chave, consulta ao dicionário (BRASIL, 1998, p. 62-63, grifos nossos).

Assim, considerando a supracitada orientação curricular federal, mostraremos, na próxima seção, como determinados materiais didáticos em uso em escolas públicas mobilizam o dicionário de Língua Portuguesa.

\section{Materiais didáticos utilizados em escolas públicas: dois exemplos para reflexão}

Após estudo teórico, selecionamos dois materiais didáticos com o objetivo de conhecer a aplicação de atividades relacionadas à lexicografia. O primeiro se trata do material didático oficial publicado 
pelo Ministério da Educação Com direito à palavra: dicionários em sala de aula (BRASIL, 2012). O segundo, do livro Para viver juntos: português (PENTEADO et al., 2009). Como o primeiro oferece orientações acerca do uso de dicionários em sala de aula, inclusive com sugestões de atividades, e o segundo é distribuído para utilização de alunos de escola pública, propusemo-nos a verificar como determinadas atividades mobilizam o uso de dicionários e o gênero verbete. O critério de escolha para a segunda obra foi o de que estivesse em uso em alguma escola pública, o que indica sua inclusão no PNLD, tendo, pois, passado por avaliação. Nossa hipótese é a de que, pelas atividades, seja possível compreender pontos de encontro e/ou desencontro entre teoria e aplicação e, assim, propor uma reflexão necessária acerca do conhecimento lexicográfico junto ao ensino nas aulas de Língua Portuguesa.

\subsection{Material didático 1}

O material didático 1 trata-se do livro Com direito à palavra: dicionários em sala de aula (BRASIL, 2012), o qual se encontra vinculado aos quatro acervos de dicionários distribuídos às escolas públicas de ensino fundamental e médio em 2012, pelo PNLD, conforme tratado anteriormente. Esse livro é composto de duas partes, mais bibliografia consultada e anexos. A primeira parte tece apontamentos teóricos acerca de lexicografia, discorre sobre as características gerais dos quatro acervos de dicionário e oferece subsídios metodológicos para explorar o potencial didático dos dicionários.

Quanto à segunda parte, dispõe-se de atividades divididas de acordo com o tipo de dicionário, a saber, tipos um, dois, três e quatro, e podem subsidiar o professor a desenvolver um importante trabalho com dicionários em aulas de Língua Portuguesa. Nesse conjunto de atividades, destacamos a atividade de número um, a qual se encontra na seção "O vocabulário e o léxico: desenvolvendo a leitura e a escrita com os dicionários de Tipo 3" (BRASIL, 2012, p. 56 ), voltada para alunos de $6^{\circ}$ a $9^{\circ}$ ano. 
A atividade selecionada, elaborada pelo professor Marcos Bagno, da Universidade de Brasília, tem como título "Com certeza ou com dúvida" e como objetivo "sensibilizar os alunos para problemas ortográficos". Para o desenvolvimento desse objetivo, o autor sugere que o professor prepare uma lista de dez a quinze palavras "normalmente mal grafadas em classe" e dite aos alunos para que coloquem cada palavra na coluna "com certeza" ou "com dúvida", demonstrando o conhecimento e a dúvida de cada aluno sobre a grafia da palavra. Depois disso, os alunos devem ser instigados a comparar suas respostas em duplas e conferirem no dicionário. É digno de nota que essa proposta orienta o professor a trabalhar com palavras que são de uso dos alunos e que em seus textos demonstram dúvidas quanto à grafia, e ao mesmo tempo estimula-os a ter o hábito de consultar um dicionário em caso de dúvida e a dialogar com o colega.

Além disso, a partir desse procedimento há a seguinte sugestão de atividade:

Você pode usar esta atividade para apresentar o vocabulário-chave de um texto ou tema que vai ser estudado. Quando os alunos estiverem conferindo a grafia correta, certifique-se de que também estão atentando para o significado das palavras novas. Pergunte se eles adivinham a que tema essas palavras estão vinculadas. Quando você entregar o texto, peça a eles que encontrem e sublinhem todas as palavras ditadas para, em seguida, conferir o sentido que elas têm nesse contexto específico (BRASIL, 2012, p. 56).

Ao sugerir que utilize esse procedimento "para apresentar o vocabulário chave de um texto ou tema que vai ser estudado”, o autor evidencia uma positiva preocupação em explorar o uso do dicionário em atividades de leitura, bem como a reflexão a partir do uso, atendendo assim aos pressupostos dos PCN de Língua Portuguesa os quais ressaltam a importância dos eixos "reflexão" e "uso" estarem interligados em atividades que envolvam o léxico. 
Há de se pensar, também, no fato de sugerir que o aluno procure no dicionário o significado das unidades lexicais de um vocabulário-chave que será utilizado depois, o que oportuniza esse aluno a perceber as diversas acepções que uma unidade lexical pode ter, dependendo do contexto de uso, dada a sua característica polissêmica por excelência. Além de aprender palavras novas e novos significados de palavras que já conhece, o aluno pode expandir seu vocabulário e repertório lexical. Nessa esteira, esse tipo de atividade descaracteriza aquelas que são propostas aos alunos por meio da imposição de glossários prontos, os quais não oferecem apoio à compreensão das palavras; pelo contrário, direcionam a leitura, impedindo que o aluno percorra seu próprio caminho de leitura, conforme poderemos observar em atividade do material didático 2 .

As questões acima ganham endosso a partir de Antunes (2012, p. 146), ao afirmar que: "Todo esse jogo traz para o centro do cenário o leitor: é ele quem avalia e quem se decide por esse ou aquele sentido; evidentemente, conjugando seu conhecimento de mundo, a informação do dicionário e os limites do texto".

As considerações realizadas corroboram, portanto, para afirmarmos que a atividade analisada dialoga com o título da seção do material na qual se encontra ("O vocabulário e o léxico: desenvolvendo a leitura e a escrita com os dicionários de Tipo 3 ”), pois está em jogo a colaboração que o dicionário pode trazer para o ensino e aprendizagem do vocabulário e léxico em atividade de leitura e de escrita, resultando em uma atividade mais significativa no ensino de língua.

\subsection{Material didático 2}

Após conferirmos o documento oficial supracitado, detivemo-nos ao segundo material - o LDLP Para viver juntos: português (PENTEADO et al., 2009), indicado ao $8^{\circ}$ ano do Ensino Fundamental. A obra apresenta uma unidade denominada "Verbete de enciclopédia e artigo de divulgação científica", 
denominação esta que nos instigou já que adiantava o tratamento a partir do gênero verbete. É a quarta unidade do livro, da página 110 a 141, e é dividida em duas partes ("Leitura 1" e "Leitura 2"), para o tratamento específico dos gêneros informados no título. Deteremo-nos às questões voltadas ao gênero verbete, ou seja, principalmente à primeira parte da unidade.

A metodologia inicial dos autores é mostrar aos alunos que verbetes enciclopédicos podem aproximá-los de realidades distantes, por exemplo utilizando como complemento uma fotografia de uma região polar. A seguir, apresentam como texto parte do verbete de enciclopédia "Regiões polares, monotonia em branco" com um glossário, ao final do texto. Seguem-se as seções: Estudo do texto, Produção de texto, Reflexão linguística e Língua viva.

O glossário é composto por nove unidades lexicais simples, como indica a figura a seguir:

\section{GLOSSÁRIO}

Espesso: grosso, compacto.

Setentrional: que é do Norte; localizado ao

Eurasiano: relativo à Eurásia (nome que se dá ao conjunto formado pela Europa e pela Ásia).

Hostil: adverso, desfavorável.

Piroga: embarcação leve, longa e estreita, cavada a fogo em um tronco de árvore.

Remoto: muito antigo; que ocorreu há muito tempo.

Seccionado: dividido. Norte.

Tundra: vegetação ártica e subártica, própria da Rússia, da Sibéria e do Canadá, que vive sobre solos rochosos e repletos de turfa (matéria esponjosa e escura formada dentro da átua por restos vegetais em decomposição) e sob frio intenso. Vaga: onda.

(PENTEADO et al., 2009, p. 113)

Questionamos a inserção do glossário como fora apresentado, acreditando que deveria haver uma forma de articular o uso do dicionário geral ou escolar junto à pesquisa das unidades lexicais pouco conhecidas. De acordo com Krieger (2007, p. 299), "os livros didáticos só muito raramente propõem exercícios que motivam o uso de dicionários", sendo pouco aproveitado seu potencial didático. Neste caso, a situação se agrava se considerarmos que a unidade versa sobre verbete. 
Entendemos, desse modo, que o formato de apresentação do glossário traduz uma prática lexicográfica reducionista, impossibilitando a aquisição e expansão lexical, bem como interfere na leitura e compreensão que o aluno pode fazer do texto, vindo a anular a autonomia do leitor junto à tentativa de tentar solucionar suas dúvidas, em detrimento do contexto que tem diante de si. Além disso, as unidades lexicais selecionadas podem não corresponder à dificuldade do público-leitor em questão. Nesse sentido, afirma Carvalho (2012, p. 35-6):

Além de haver uma antecipação das palavras que poderiam suscitar dúvidas, o que implica desconsiderar a possibilidade de o aluno-leitor conseguir entender os sentidos daquelas palavras, com seus conhecimentos e vivências e com base em elementos do contexto, muitos desses glossários não realizam de maneira satisfatória a única tarefa a que se propõem realizar: explicitar o significado do vocabulário de textos selecionados para públicos de determinada etapa escolar.

Em "Estudo do texto", há exercícios que procuram resgatar as informações do texto, explorar sua estrutura, contexto e linguagem. As atividades apresentadas são importantes, mas enfatizam muito a estrutura do texto (o que não deixa de ser necessário); então, sugerimos que poderia haver uma atividade que mostrasse a diferença entre o verbete de enciclopédia e o verbete de um dicionário geral ou escolar, já que os alunos estão mais familiarizados com esses últimos gêneros. Entendemos que a unidade é específica, mas tal diferenciação poderia auxiliar na concepção ampla que os alunos estão adquirindo sobre a lexicografia.

Gostaríamos de destacar os quadros informativos da seção, a partir dos quais os autores orientam: livros impressos ainda podem ser considerados fontes mais seguras de informação; a credibilidade da enciclopédia on line Wikipédia deve ser questionada, já que há liberdade total de edição por parte dos internautas; a dinamicidade do mundo implica na constante 
atualização das enciclopédias; e ainda a ilustração do fac-símile da capa da primeira enciclopédia, elaborada no século XVIII.

A seção "Produção de texto" traz a seguinte proposta:

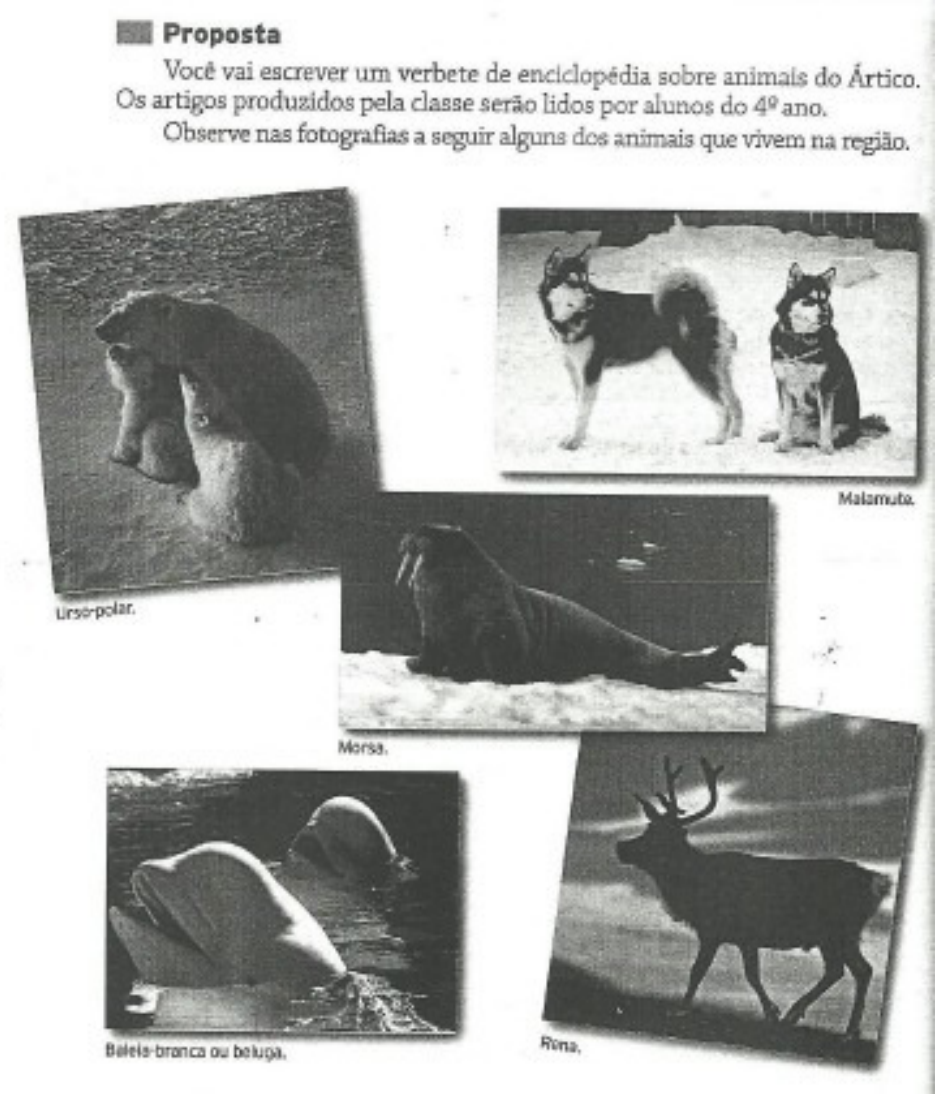

(PENTEADO et al., 2009, p. 118)

Na página seguinte, os autores instruem os alunos acerca da elaboração do texto, devendo estes tratarem de três dos animais "sugeridos". Apesar de ser explicitado no início da unidade que os verbetes enciclopédicos podem nos aproximar de realidades distantes (PENTEADO et al., 2009, p. 111), acreditamos que a elaboração de um texto no referido gênero seria mais produtiva se considerasse o conhecimento de mundo dos alunos, já que 
neste gênero é feita uma descrição de referentes do "mundo real", não de signos. Assim, se o aluno pudesse escolher o referente a ser descrito, certamente a motivação seria um diferencial junto à elaboração do texto. Em relação à circulação do texto produzido, a proposta é a de que os verbetes sejam expostos em um mural, exposição esta por nós questionada, pois verbetes são elaborados para circular num outro tipo de suporte, vindo a reforçar a sugestão de os referentes serem escolhidos pelos alunos, de modo a gerar uma diversidade de referentes descritos, o que propiciaria a organização do material no formato de apresentação de uma enciclopédia, recebendo encadernação com disposição em ordem alfabética.

Num segundo momento, tomando como ponto de partida o quadro informativo sobre a credibilidade da enciclopédia livre Wikipédia, o professor poderia desenvolver, ao mesmo tempo, um trabalho de orientação e produção textual mostrando aos alunos que eles também podem ser autores (inserindo os verbetes elaborados em sala de aula) e/ou colaboradores (inserindo informações sobre os referentes pesquisados nos verbetes já incluídos na enciclopédia). Dessa forma, os alunos conheceriam o gênero verbete de enciclopédia virtual livre fazendo suas produções circularem num segundo suporte, atividade esta que somaria para que eles entendessem as adequações ao gênero de acordo com o suporte de circulação.

Na segunda parte da unidade (PENTEADO et al., 2009, p. 137), após trabalharem o segundo gênero, os autores sugerem a leitura do livro "Pequeno dicionário de palavras ao vento", demonstrando três dos verbetes da obra. Informam que "Como em um dicionário tradicional, os verbetes são curtos, porém a autora fez uso do humor e da linguagem figurada para escrevêlos". Propõem, então, o seguinte: "Inspirado pelos verbetes de Adriana Falcão, crie, em seu caderno, verbetes para os seguintes vocábulos: Adeus, Ignorância, Paixão". Tal proposta corrobora a necessidade de diferenciação entre um dicionário e uma 
enciclopédia, no início da unidade, mesmo considerando que os alunos já estejam familiarizados com dicionários gerais ou escolares, lembrando que há dicionários, enciclopédias e dicionários enciclopédicos, reforçando a preocupação em apresentar a tipologia lexicográfica de forma coerente aos alunos.

\section{Considerações finais}

Em uma crônica intitulada "O livro da solidão", Cecília Meireles (1948) afirma que se lhe perguntassem qual livro levaria para uma ilha deserta, este seria um dicionário: "Eu levaria o Dicionário para a ilha deserta. O tempo passaria docemente, enquanto eu passeasse por entre nomes conhecidos e desconhecidos, nomes, sementes e pensamentos e sementes das flores de retórica". Enumera suas qualidades, mas lamenta "que não ensinem as crianças a amar o dicionário".

Lidar com atividades que versem acerca do uso de dicionários e do gênero verbete em materiais didáticos utilizados na Educação Básica pôde nos mostrar o quanto a escola precisa ensinar aos alunos (com o devido estabelecimento de critérios necessários ao trabalho) a importante função de utilização dos dicionários. Ao discutirmos a mobilização destes em atividades nos referidos materiais didáticos, o foi no sentido de colocar em reflexão um conteúdo pouco discutido tanto na academia quanto nas escolas, mesmo estando presente em orientações curriculares nacionais.

Assim, acreditamos que, para que haja uma adequada utilização do dicionário em sala de aula de forma a contribuir para a compreensão de questões da língua, especificamente do léxico, é preciso fomentar discussões/reflexões acerca dos pressupostos da lexicografia entre os profissionais envolvidos no processo de ensino aprendizagem, evitando propostas reducionistas como a analisada na seção 5.2, as quais ajudam a excluir o dicionário da lista de opções de livros que os alunos possivelmente levariam para uma ilha deserta. 


\section{Referências}

ANTUNES, Irandé. Território das palavras: estudo do léxico em sala de aula. São Paulo: Parábola Editorial, 2012.

BIDERMAN, Maria Tereza Camargo. A ciência da lexicografia. In: (Org.). Alfa. Revista de Linguística. Lexicologia e lexicografia. São Paulo: Universidade Estadual Paulista, v. 28 (suplemento), p. 1-26, 1984.

BIDERMAN, Maria Tereza Camargo. As ciências do léxico. In: OLIVEIRA, Ana Maria Pinto Pires de; ISQUERDO, Aparecida Negri (Org.). As ciências do léxico: lexicologia, lexicografia e terminologia. v. I. Campo Grande: Ed. UFMS, 1998. p. 11-20.

BRASIL. Parâmetros Curriculares Nacionais: terceiro e quarto ciclos do Ensino Fundamental: Língua Portuguesa. Brasília-DF: SEF/MEC, 1998. Disponível em: <http://portal.mec.gov.br/seb/arquivos/pdf/portugues. pdf $>$. Acesso em: 31 mar. 2013.

BRASIL. Com direito à palavra: dicionários em sala de aula. Elaboração Egon Rangel. Brasília-DF: MEC/SEB, 2012. PNLD 2012: Dicionários.

CARVALHO, Orlene Lúcia de Saboia. Glossários em livros didáticos e dicionários escolares: da redução à expansão lexical na compreensão de textos. In: Interdisciplinar: Revista de Estudos de Língua e Literatura. Ano VII, v. 16, p. 30-45, 2012. Disponível em: < http:// 200.17.141.110/periodicos/interdisciplinar/revistas/ARQ_INTER_16/ INTER16_003.pdf>. Acesso em: 13 maio 2013.

CORACINI, Maria José Rodrigues Faria (Org.). Interpretação, autoria e legitimação do livro didático: língua materna e língua estrangeira. 2. ed. Campinas. Pontes: 1999.

COUTINHO, Ismael de Lima. Pontos de gramática histórica. 7. ed. rev. Rio de Janeiro: Ao Livro Técnico, 1976.

FERNÁNDEZ, Dolores Azorín. La investigación sobre el uso del diccionario en el ámbito escolar. In: ISQUERDO, Aparecida Negri; ALVES, Ieda Maria (Org.). As ciências do léxico: lexicologia, lexicografia, terminologia. v. III. Campo Grande, MS: Ed. UFMS; São Paulo: Humanitas, 2007. p. 169-191. 
KRIEGER, Maria da Graça. O dicionário de língua como potencial instrumento didático. In: ISQUERDO, Aparecida Negri; ALVES, Ieda Maria (Org.). As ciências do léxico: lexicologia, lexicografia, terminologia. v. III Campo Grande, MS: Ed. UFMS; São Paulo: Humanitas, 2007. p. 295-309.

MEIRELES, Cecília. O livro da solidão. Folha da manhã, São Paulo, 11 jul.1948. Disponível em: < http://www.releituras.com/cmeireles olivro.asp >. Acesso em: jul. 2013.

PENTEADO, Ana Elisa de Arruda et al. Para viver juntos: português, $8^{\circ}$ ano, ensino fundamental. 1. ed. rev. São Paulo: Edições SM, 2009.

WELKER, Herbert Andreas. Dicionários: uma pequena introdução à lexicografia. 2. ed. revista e ampliada. Brasília: Thesaurus, 2004.

Recebido para publicação em 30 de julho de 2013 Aprovado em 2 de outubro de 2013 